\title{
Patients, prisoners, or people? Women prisoners' experiences of primary care in prison: a qualitative study
}

\author{
Emma Plugge, Nicola Douglas and Ray Fitzpatrick
}

\section{ABSTRACT}

Background

The development of primary care services within prisons has been central to improvements in the provision of health care in this setting over the past decade. Despite national imperatives to involve patients in the development of services and numerous policy initiatives, there has been no systematic evaluation of changes in the delivery of primary care and little published evidence of consultation with prisoners.

Aim

To explore women prisoners' experiences of primary healthcare provision in prison.

Design of study

Qualitative study using focus groups and interviews.

Setting

Two women's prisons in southern England.

Method

Six focus groups involving 37 women were conducted, as well as 12 semi-structured individual interviews. Focus groups and interviews were recorded, transcribed, and analysed thematically.

\section{Results}

Women prisoners' perceptions of the quality of prison health care were mixed. There were accounts of goodquality care where practitioners were regarded as knowledgeable and respectful, but many perceived that the quality of care was poor. They complained about difficulties accessing care or medication, disrespectful treatment, and breaches of confidentiality by practitioners. They voiced the belief that staff were less qualified and competent than their counterparts in the community.

\section{Conclusion}

The prison environment presents unique challenges to those providing health care, and much work has been done recently on modernising prison health care and improving professional standards of practice. However, the accounts of women prisoners in this study suggest that there is a gap between patient experience and policy aspirations.

Keywords

prisoners; qualitative research; quality of health care; women.

\section{INTRODUCTION}

The development of primary care services within prisons has been central to improvements in the provision of health care in this setting. ${ }^{1}$ Since 1999 there have been a number of policies aimed at developing and improving the way in which health care is provided in prisons. Central to these developments has been the notion of 'equivalence' of care: that prisoners should have access to the same quality and range of health care as the general public receives from the NHS. ${ }^{2}$ Furthermore, a number of key initiatives have focused on the importance of primary care in delivering high-quality, effective health care to prisoners.

Health professionals practising in prisons face a number of challenges; for example, professional isolation, a lack of understanding by other prison staff of the value of health care, ${ }^{3}$ and working with a socially marginalised group of patients with considerable health needs, particularly relating to mental health and substance misuse. ${ }^{4,5}$ Many of the issues facing these health professionals have been recognised, and there have been considerable changes to the way in which health care is delivered in prisons.

Health care in prisons is now commissioned and

E Plugge, MA, DPhil, MFPH, senior research scientist; N Douglas, BA Hons, researcher; R Fitzpatrick, BA, $M S c, P h D$, professor of public health and primary care, Department of Public Health, University of Oxford, Oxford.

Address for correspondence

Emma Plugge, Department of Public Health, University of Oxford, Old Road Campus, Old Road, Oxford, OX3 7LF.

E-mail: emma.plugge@dphpc.ox.ac.uk

Submitted: 15 January 2008; Editor's response: 26 March 2008; final acceptance: 23 April 2008.

(C) British Journal of General Practice

This is the full-length article of an abridged version published in print. Cite this article as: Br J Gen Pract 2008; DOI: 10.3399/bjgp08X330771 
provided by the NHS, and there is a recognition that GPs working in prisons should not only be appropriately trained to deliver primary care but that they should also work in the wider community. ${ }^{6}$ Similarly, there have also been developments concerning the professional practice of other primary care staff. ${ }^{7-9}$ However, there has been no systematic evaluation of the changes in the delivery of primary care and little published evidence of consultation with prisoners themselves, despite the national imperatives to involve patients in the development of services. ${ }^{10}$ This study aimed to explore women prisoners' experiences of healthcare provision, as part of a wider project examining the impact of imprisonment on women's health.

\section{METHOD}

\section{Setting}

The focus groups were conducted in two prisons in southern England. Both were closed, local prisons that received women prisoners from the community who were on remand or had been sentenced. The focus groups and interviews took place in a private room in the health centre of the prisons or on the wings. No prison or healthcare staff were present in the room and it was made clear to the women that what was said in the groups and interviews was confidential. It was emphasised, however, that if they revealed an intent to escape or harm themselves or another person, confidentiality would have to be broken.

\section{Participants}

Purposive sampling was used to recruit women to six specific focus groups to ensure that the perspectives of women from a range of different prison groupings were included. Although the groups were very different from each other, the members within a group were fairly homogenous in terms of background; this is the best way to identify a broad range of views from those from different backgrounds. ${ }^{11}$ The researchers identified women who were eligible for the study using the local inmate directory; only women who had been in prison for at least 1 month were considered eligible.

The researchers approached women on the wings at least 1 day before the group to give them a written information sheet and ensure they were able to attend if they wished to. Written consent was obtained at the time of the group. There was a facilitator and cofacilitator for each group, and the conversation was guided by a schedule (Box 1) and tape-recorded.

Convenience sampling was used to recruit women to participate in individual interviews. These women were participating in a longitudinal questionnaire survey over a 3-month period and so were familiar

\section{How this fits in}

Prison is a challenging environment for primary care practitioners. Considerable changes and improvements in the delivery of services have taken place since 1999. However, there have been limited studies examining patients' perceptions and experiences of primary health care in this environment. Despite policy and service delivery changes, patients hold very negative views about healthcare services in prison; in particular, they are concerned about access to treatment or medication, the attitudes of healthcare staff, and breaches of confidentiality. There is also a belief that staff are less qualified and competent than professionals based in the community.

with the researchers. The semi-structured interviews were conducted when the women had been in prison for between 1 and 3 months. None of the interview participants had participated in the focus groups. Written consent was obtained and the interviews were tape-recorded. The questions contained within the interview schedule (Box 2) reflected the key themes that emerged from the focus groups.

\section{Data analysis}

The recordings of both the focus groups and interviews were transcribed using a private company. Two of the authors independently analysed the data. Having become familiarised with the data, the researchers carried out thematic analyses to identify and categorise major themes and subthemes. The transcripts were independently coded and then searched for themes by collating codes into potential themes. The themes were then reviewed and refined to ensure they formed a

\section{Box 1. Topics covered during the focus groups.}

- What being 'healthy' means.

- Experience of healthcare services in prison.

- Experience of care provided by specific groups: nurses, doctors, dentists, and visiting specialists.

- Ways in which health services might be developed.

\section{Box 2. Specific questions asked during the interviews.}

- Can you tell me about any experiences you have had with prison healthcare services since you came to prison (this time)? [Probe for both positive and negative experiences.]

- Overall, how would you rate the healthcare services you have received in prison compared with health care you have received outside? [Probes: staff attitude, quality of care, access to care and medicines, lack of confidentiality. If interviewee reports witnessing adverse incidents (for example, self-harm, suicide, and seizures), probe for personal impact of this.]

- If you could make three suggestions on how to improve prison health care what would they be? 


\section{Table 1. Focus group composition.}

\begin{tabular}{llc} 
Group & Characteristic & Number of participants \\
\hline 1 & Young offender (aged 18-21 years) & 11 \\
\hline 2 & Black British & 5 \\
\hline 3 & Jamaican & 3 \\
\hline 4 & Sentenced prisoner & 6 \\
\hline 5 & African & 7 \\
\hline 6 & Drug misuser & 5 \\
\hline Total & & 37 \\
\hline
\end{tabular}

coherent pattern and to recode if necessary. Data were also examined for deviant cases, that is, data that did not fit with the themes.

When each researcher had independently identified the themes, they discussed the interpretation of the data. The few minor differences in interpretation were resolved by discussion. NVivo software (version 7) was used to facilitate data coding and organisation into conceptual categories and themes.

\section{RESULTS}

There were six focus groups comprising young offenders, prisoners who had been sentenced, drug misusers, and women who described themselves as black British, Jamaican, and African (Table 1). Twelve women were interviewed and, of those, 11 were British born and one was Irish. Four described themselves as black (African or African-Caribbean), the remainder as white. They ranged in age from 19 to 46 years.

Women were very dissatisfied with the health care provided in the prison, although some gave examples of good-quality care. They particularly valued those professionals who appeared compassionate and caring, and were genuinely concerned for their welfare:

'Nurse [name removed] is wicked! It's not because she's just helped me but she helps a lot of people. It's not just because she's there as a nurse, she does take time out, she will listen. She is a genuine person.' (Interview 8)

Only a minority of women, however, held these views; the themes that emerged from the data reflected the negative views of the provision that were held by the majority of participants.

\section{Difficulties with accessing care}

Access to health care was important for many of the women. Two important features of the system that they felt denied them adequate access to healthcare staff were the application process and 'gatekeeping'.
The application process. Women had to complete a form (an 'app'), stating why they needed to see a particular professional. This was then posted into a box on the wing and collected by the nurses (or, in some cases, the prison officers), who read it and decided who would and would not be seen. Women were not kept informed about the status of their application, and were not told whether an appointment would be arranged or how long they would have to wait:

'This app business - do you know how long it takes to see a doctor here? I would have damned killed myself if I wanted to do that.' (Focus group 1)

'When you need to see a doctor, you have to put in an application, you have to wait too long and mainly because I'm quiet and because I don't fuss.' (Focus group 3)

'When you are in pain ... you can't just book like you can't just go to your GP or go to - walk in to a surgery and say "I'm ill, blah, blah, blah". They'll tell you to put an app in and it can take you a whole week and you're still waiting for that app.' (Focus group 5)

'Yeah everything's a [expletive] app. I can't be bothered ... because of the pain I'm in, do you know what I mean? Everything's so long - I've been waiting for [expletive] 6 weeks.' (Focus group 6)

'Gatekeeping'. Aside from the perceived delays that occurred as a result of the application process, there was the more subtle issue of 'nurses as gatekeepers'. They were seen as people who had the power to deny prisoners access to the doctor or other health professionals, either through the application process or by their presence in the consulting room, which some women felt disrupted any therapeutic relationship:

'You can't just say, "I want to see a doctor". You've got to explain to the nurse why you want to see a doctor and if the nurse - if she thinks it's valid then you can. If she thinks it's not worth it because you was there last week ... then you ain't gonna see him.' (Focus group 6)

'The nursing staff decide whether you're eligible to go to the doctor or not.' (Focus group 4)

'The nurses to me seem only there to filter out 
the applications for the doctor and to interrupt you when you're at the doctor and tell the doctor what's wrong with you, as if you cannot speak for yourself.' (Focus group 4)

'It doesn't feel welcoming, you know, if you've got your "bodyguard" nurse with you while you're talking to the doctor, who interprets your symptoms for you, as if you're not capable of explaining to the doctor in your own words. And then I have been taken for an examination in the adjoining room where there have been three nurses present while I'm getting undressed.' (Focus group 4)

'Listen, if you want to see a doctor here you have to wait until the nurse slips out the room and quickly say all you've got to say to the doctor and they can write down your med [medication] because the nurse will stop you getting anything you know and that's wrong - that's wrong.' (Focus group 2)

\section{Difficulties accessing medication}

In addition to difficulties accessing health professionals, women also experienced difficulties obtaining the medication they felt they needed. Many told how, on entering prison, they had been denied the medication they had been prescribed in the community. The reasons for the discontinuation of treatment were often unclear or inadequate, adding to their frustration:

'When I was coming off my detox - they're supposed to give you sleeping medication, because after you come off your methadone you don't sleep. I hadn't slept for about 7 days and I was wing cleaning and doing the drug course, so I was proper frazzled. I was like, "Listen, I need some medication, I need to sleep at night". And he was like, "No, we're not giving out medication".' (Interview 6)

'He's telling me he's not giving no antidepressants and I said "but I get it from my doctor" and he said "well, we'll have to get in contact" ... I'm telling him that antidepressants [are] what I take and he just says "no, no, no, you just want it because other people take it".' (Focus group 2)

I've seen a psychiatrist for two-and-a-half, nearly three years I think, and he's put me on medication, which I was quite happy to be on. It stopped when I come in here. Everything stopped, and I'm a bit cheesed off.' (Interview 8)
'Yeah and obviously l'm on the contraceptive pill because of my lack of hormones due to these [health problems] and of course it, they don't get my contraceptive pill to me on time, which causes my spots. You know, I have to tell them, I get a month's supply at a time, so I get 21 tablets. Then I'll go to them a week before my tablets run out and say "Right you've got 2 weeks, can you get them?". I've waited a month for [them], and I've never had a break off these pills for 9 years, since I came here, until I came here and then they said, they kept saying that there was a problem with the pharmacy and they hadn't dispatched them and this, that, and the other, and they were just fobbing me off.' (Focus group 4)

\section{The attitude of primary care staff}

Women had much to say about the attitude of the healthcare staff. They were very critical, in part because they felt that the disrespectful and uncaring attitude of the staff was not appropriate for the caring professions, and that they were not treated as they would be in the community:

'They make you feel - oh ... I can only speak for myself, but I - they make you feel like that you - you're [sighs]. They look beneath you. Erm, down at you, if you know what I mean? Because you - you're a prisoner.' (Interview 8)

'They come straight up and they say "Oh you need to see the doctor about this", or "You need to see the doctor about that". And the other day the lady came up to me in front of everybody and said, "Oh you know you haven't given your urine sample, here's the bottle, can you ..." I mean, you know I find it really upsetting because it's just another indication of, that you're not really treated ... as if you're entitled to the same standard of health care that you would enjoy outside. I wouldn't be spoken to like that.' (Focus group 4)

'I think the nursing in here is very ... I don't think they understand. I don't think they want to understand. They have a very bad attitude.' (Interview 1)

'To me it's just like they're just not interested. You know, the way I see it is you're here to do a job, you get paid to do it. I would have thought to work here, to be a nurse and to work in the prison system you would have to have some kind of form of caring, some form of compassion for people. It's not there. And if you don't like your job or you don't want to do what you're paid to do, don't work here. Simple as that.' (Interview 6) 
The women complained that staff judged them without listening to them, and that this was related to their status as prisoners:

'The doctors come from outside to work in prison and they know what they're coming here to do, they're coming to work with prisoners, so I don't see how they can treat people different because they know it. They come here and they know that they're going to be working with convicted criminals, non-convicted criminals, mental patients, anything! And they should know how to treat people and they get taught social skills outside and they shouldn't treat anyone differently.' (Focus group 1)

'You shouldn't be judged just because you're in prison.' (Focus group 1)

'That's it, they need to listen and try to understand.' (Focus group 2)

Furthermore, the women perceived that there was an assumption that all illness was drug related and, therefore, could be ignored as it was self-inflicted:

'Not stereotyping - stop being stereotypical and thinking that we just want drugs.' (Focus group 2)

'I think they say like it's self-inflicted so their attitude for people coming off the drugs is like "You brought it on yourself, tough [expletive]".' (Focus group 6)

'I was being sick and I didn't know what was the matter with me - but they presume because I was coming off heroin and l'd just took my methadone 2 days before I started being sick, they just presumed I was still [detoxing], yeah they left me for 4 days being sick, yeah, and then in the end they had to take me to a outside hospital.' (Focus group 2)

\section{Professional competence}

The professional competence of healthcare staff was frequently called into question, and women often referred to 'reject' staff. At times, they used this term casually, as if it were part of the common vocabulary, but sometimes their use of it was illustrated with accounts of what they considered to be mismanaged illnesses. There were comments indicating that the healthcare staff were not considered competent:

'The doctors and nurses - I just think they're rejects.' (Focus group 2)
'They are, they're NHS rejects.' (Focus group 2)

'First of all these nurses are unprofessional. I don't know where they get them from. l'd like to see some of them's qualification. Trust me, because - and first of all, they don't even notice, interact with you on a professional basis.' (Focus group 3)

'I don't rate them that they're qualified doctors. I reckon they just [expletive] got them off the street yeah.' (Focus group 1)

'... there's only one proper nurse on our unit.' (Focus group 1)

'They're like dinner ladies ... just sat there ... I had a really bad kidney problem and they saw for 3 days and 3 nights I hadn't eaten and I was pregnant at the time, I had to go to hospital and I was on a drip when I was in hospital for 14 nights and 14 days, that's how serious it was. And they were like "There's nothing wrong with you", "Then what's this on my face? Well, tell me what it is and I'll believe you" and she goes "Well I can't because I'm not a doctor" - exactly. You know, offering me paracetamol, you know, paracetamols.' (Focus group 1)

\section{Confidentiality}

Women were aware that health care was often not delivered in the way it that might be in the community. The lack of confidentiality and privacy was of great concern to many. They cited several examples of times when they felt that confidentiality had been breached:

'They come up, the nurses come up to you in the corridor, talk to you about your medical problem that you've reported. They've no consideration how that might, that you might find that embarrassing. Or you might not want everybody on your wing to know that you've got a urine infection. Do you know what I mean? I mean, well, there's this assumption that, that it's ok. You wouldn't get a nurse outside coming up to you in a public place and discussing what is wrong with you.' (Focus group 4)

'There's no privacy. Every time we go to discuss something it has to be through the hatch [in the prison door]. Now when someone else round the corner is having a discussion with the nurse, I can hear what they're saying and what's going on. There's no privacy ... you should have privacy to the nurse if you want to speak to her.' (Focus group 6) 


\section{Working in difficult circumstances}

Some women did try to put the poor provision into context, highlighting the vulnerable and difficult patient group, and the problems in a system that is forced to deal with such a high turnover of prisoners:

'Like there's one nurse, yeah, for however many people they have to see coming through reception here. Like $40 \%$ of them might be alcoholics or drug addicts, they've got to take on board everything that everyone is saying. Most of the people that come in "clucking" or withdrawing, they want their drugs and they want whatever is going to make them feel better now. And then they've got to listen to the other people, so the doctor's had a really [expletive] customer - patient, sorry - and then someone else comes along that's being genuine, then that person might have it taken out on them. But that's how the doctor feels - they've got to understand.' (Focus group 1)

'There's so much coming and going, like people coming in, people leaving, people going to different wings, going to court, coming back your file's gone and it's come back, it's come up late. But I think some of it is not their fault, do you know what I mean, I'm not blaming it 100\% on them.' (Interview 6)

\section{DISCUSSION}

\section{Summary of main findings}

Women prisoners tended to be very critical of primary care provision in prison. They were particularly critical of difficulties accessing care and medication, the attitude and perceived competence of staff, and the lack of confidentiality. However, some women identified ways in which the healthcare services had helped them, and some could appreciate the very difficult conditions in which staff members work.

\section{Strengths and limitations of the study}

This study aimed to explore women prisoners' experiences of primary healthcare provision in prison. Qualitative methods are the most appropriate means to explore and understand people's experiences, attitudes, and views, ${ }^{12,13}$ and have been widely used to explore public understanding of health and illness. ${ }^{14}$ Furthermore, qualitative methods are particularly useful in areas that have previously been poorly researched, as is the case with this research topic; and combining methods can be particularly effective in this situation..$^{12}$ As such, in this study two different methods were used sequentially: focus groups followed by one-to-one semistructured interviews. Although the focus groups were used to inform the development of specific questions asked in the interviews, which were used to explore these areas in more depth, the groups produced a great deal of rich data.

Focus groups were also particularly suitable for this situation because this method potentially offers greater opportunities for the redistribution of power from researchers to participants, which is very useful when trying to explore and understand issues from the perspective of vulnerable individuals, as in the case of women prisoners. ${ }^{15}$ Furthermore, this method is particularly suitable for women who have a tradition of sharing personal information with other women ${ }^{16}$ and allows for the inclusion of people who cannot read or write; ${ }^{14}$ low literacy levels are a feature of this population. ${ }^{17}$

Although the qualitative methods used were appropriate for the study question, and the women's accounts were credible with key themes being repeated across interviews and focus groups, further validation of the findings should ideally have been undertaken. The findings would have been presented to the women prisoners themselves, but this was not possible as 6 months passed between the final interview and a full analysis of the data when the majority of prisoners had been released.

Furthermore - and very importantly - the data provide only a partial account, and the researchers would have liked to explore in depth the beliefs and understandings of prison staff. Had the resources and time been available to include prison professionals, they no doubt would have had much to say that would have explained, contradicted, and expanded upon the contributions from the women prisoners. There are always multiple meanings and interpretations that can be made of any social process, including the provision of health care.

Resource constraints meant that the researchers could only present the key findings from the quantitative data to one small group of staff (fewer than 12 members) in one of the prisons for discussion. The staff were helpful in 'contextualising' the findings, and provided some - albeit limited validation of these. For example, the findings show that women perceived that GPs were unreasonably withholding antidepressant and sleeping medication. The staff discussed the fact that there were protocols in place for the prescription of these drugs, based on what was considered good clinical practice. As such, although the prisoners perceived that denial of these drugs denoted an uncaring staff attitude and indifference to their needs, it is more likely to indicate that health professionals are responsive to previous criticisms that women prisoners have historically been an overmedicated population, and are keen to follow best clinical practice from community settings. 
Purposive sampling helped to ensure the broadest expression of opinion, but it is not possible to generalise these findings across the whole women's prison estate. The findings from the focus groups and interviews were remarkably consistent across the heterogeneous groups and individuals; however, there were some discrepant cases, such as those women who felt that they received good care in prison and always cited a particular member of staff who had helped them.

This research took place during a period of considerable change in the organisation and delivery of prison health care in England and Wales, with the transfer of responsibility at the local level from individual prisons to primary care trusts. Therefore, this research represent a particular historical moment, and it can only be speculated whether the advances in this area have significantly altered the perspective on healthcare provision in prisons.

\section{Comparison with existing literature}

Although positive accounts were forthcoming, it was more frequently the case that women used the opportunity presented by the interviews and focus groups to detail their complaints about healthcare services. When patients are asked about health service quality, they are more likely to focus on perceived shortcomings than positive aspects; this effect has been observed elsewhere and it is widely acknowledged that gauging patient satisfaction in health care is problematic. ${ }^{18,19}$ It is also interesting to note that focus group participants and interviewees were critical of prison health care. Cornwell, ${ }^{20}$ in her study of the lives of 24 people living in East London, found that people were complimentary in public but in interviews would be more critical; she noted that these findings were in contrast to those of Stimson and Webb, who found that people tended to be more critical of health professionals when they had an 'audience'. ${ }^{20}$ In the present study, no such differences between focus groups and individual interviews were noted.

Nevertheless, concerns about access to, and the quality of, prison healthcare services have been raised not only by prisoners, ${ }^{21-23}$ but also by those professionals responsible for inspecting prisons. ${ }^{24}$ These concerns were, in part, the stimulus to effect change with regard to the way in which health care is provided in prison. ${ }^{2,3}$ It should be emphasised that since 1999 there have been considerable developments in the provision of health care, and the most recent annual report of the Chief Inspector of Prisons for England and Wales (2005-2006) acknowledges that since 2000 there have been significant improvements in the quality of health care. ${ }^{25}$

\section{Implications for future research and clinical practice}

The prison environment presents unique challenges to providing health care. As one GP stated:

'Most GPs outside don't run surgeries with three drug addicts, four schizophrenics, two hepatitis C-positive patients, and a couple of diabetics. In the community that would be a nightmare session. In prison it's just a normal day'. ${ }^{26}$

Despite the considerable health needs of prisoners, primary healthcare staff in prisons have historically lacked the professional support systems available in the community, and there have been concerns about the quality of primary care. Although much work has been done recently on modernising prison health care and improving professional standards of practice, the accounts of women prisoners in this study suggest that more could be done in prisons to improve communication between healthcare staff and prisoners. This might include the development of regular consultations with prisoners on services, or simpler measures such as putting photographs of staff in the healthcare facility with their name and qualifications for the prisoners to see. Other simple actions that might benefit relations between patients and staff include women being informed that their 'app' has been received, as well as details of when they will be seen, and by whom.

The participants in this study felt that, on the whole, the attitude of staff was poor. However, this study does not provide conclusive evidence that this was so; prisons are socially contested sites and healthcare staff may be seen as part of the establishment and, therefore, a legitimate target for criticism. Although there is no evidence or reason to believe that the researchers in this study were given deceptive or misleading accounts, the fact that prisoners were being asked, in part, to discuss institutions and individuals who were involved in the processes of detaining them against their will must be given due accord.

As already noted, prisons are difficult working environments and more could be done to support healthcare staff in their work. For example, those commissioning services need to ensure adequate staffing levels so that health professionals have adequate time, not only to deal appropriately and sympathetically with the complex needs of their patients, but also for other activities, such as professional development, so they do not 'burn out'. Consideration should also be given to adopting the same working model for both doctors and nursing staff; nursing staff, like GPs, should continue to work at least part of the week in the NHS in the community. 
Finally, further research should be conducted within the next few years to determine whether the significant developments and improvements evident to those commissioning and providing primary healthcare services in prison are also evident to the prisoners themselves.

\section{Funding body}

The University of Oxford is grateful to the King's Fund for providing a grant to help with the cost of this study. Any views expressed in this publication are those of the authors and not necessarily those of the King's Fund, which is not responsible for them (03-191)

\section{Ethical approval}

Approval was granted by the South East Multicentre Research Ethics Committee in June 2004 (04/MRE01/14)

\section{Competing interests}

The authors have stated that there are none

\section{Acknowledgements}

We are very grateful to all the women who participated in this study, to the prison officers and healthcare staff who facilitated access to these women, and to HMPS Women and Young People's Group

\section{Discuss this article}

Contribute and read comments about this article on the Discussion Forum: http://www.rcgp.org.uk/bjgp-discuss

\section{REFERENCES}

1. Department of Health and HM Prison Service. Developing and modernising primary care in prisons. London: Department of Health, 2002.

2. Joint Prison Service and National Health Service Executive Working Group. The future organisation of prison health care. London: Department of Health, 1999.

3. Her Majesty's Inspectorate of Prisons for England and Wales. Patient or prisoner? A new strategy for health care in prisons. London: Department of Health, 1996.

4. Fazel S, Danesh J. Serious mental disorder in 23000 prisoners: a systematic review of 62 surveys. Lancet 2002; 359(9306): 545-550.

5. Fazel S, Bains P, Doll H. Substance abuse and dependence in prisoners: a systematic review. Addiction 2006; 101(2): 181-191.

6. Department of Health. Good medical practice for doctors providing primary care services in prison. London: Department of Health, 2003.

7. Department of Health. A pharmacy service for prisoners. London: Department of Health, 2003.

8. Department of Health. Nursing in prisons: report by the working group considering the development of prison nursing, with particular reference to health care officers. London: Department of Health, 2000.

9. Department of Health. Strategy for modernising dental services for prisoners in England. London: Department of Health, 2003.

10. Department of Health Patient and Public Involvement Team. A stronger local voice: a framework for creating a stronger local voice in the development of health and social care services. London: Department of Health, 2006.

11. Fitzpatrick R, Boulton M. Qualitative methods for assessing health care. Qual Health Care 1994; 3(2): 107-113.

12. Pope C, Mays N. Qualitative research: reaching the parts other methods cannot reach: an introduction to qualitative methods in health and health services research. BMJ 1995; 311(6996): 42-45.

13. Ziebland S, Wright L. Qualitative research methods. In: Jenkinson $\mathrm{C}$ (ed.). Assessment and evaluation of health and medical care. Buckingham: Open University Press, 1997: 102-128.

14. Kitzinger J. Qualitative research: introducing focus groups. BMJ 1995; 311(7000): 299-302.

15. Owen S. The practical, methodological and ethical dilemmas of conducting focus groups with vulnerable clients. J Adv Nurs 2001; 36(5): 652-658.

16. Kitzinger J. The methodology of focus groups: the importance of interaction between research participants. Sociol Health Illn 1994; 16(1): 103-121.
17. Home Office. Statistics on women in the criminal justice system. London: Home Office, 2001.

18. Coulter A. Trends in patients' experience of the NHS. Oxford: Picker Institute Europe, 2006.

19. Coulter A. Can patients assess the quality of health care? $B M J$ 2006; 333(7557): 1-2.

20. Cornwell J. Doctors and health services. Hard-earned lives. London: Tavistock Publications, 1984.

21. Howerton A, Byng R, Campbell J, et al. Understanding help seeking behaviour among male offenders: qualitative interview study. BMJ 2007; 334(7588): 303-310.

22. Nurse J, Woodcock P, Ormsby J. Influence of environmental factors on mental health within prisons: focus group study. BMJ 2003; 327(7413): 480-485.

23. Condon L, Hek G, Harris F, et al. Users' views of prison health services: a qualitative study. J Adv Nurs 2007; 58(3): 216-226.

24. Reed J, Lyne M. The quality of health care in prisons: results of a year's programme of semistructured inspections. BMJ 1997; 315(7120): 1420-1424.

25. HM Chief Inspector of Prisons for England and Wales. Annual report. London: The Stationery Office, 2007.

26. HM Prison Service. They're not just patients or prisoners. They're people. http://www.dh.gov.uk/en/Publicationsandstatistics/ Publications/ PublicationsPolicyAndGuidance/DH_4070151 (accessed 28 Jul 2008) 